\section{Blood Glucose and Nutritive Antibiotic Activity in Ruminants}

Numerous monogastric species respond to the continuous ingestion of small amounts of certain antibiotics by increased growth and improved feed utilisation. The mode of action of this so-called "nutritive effect" is not well understood, although various alterations in the intestinal flora have been observed as well as changes in the intestinal mucosa, indicating improved nutrient absorption.

Ruminants also exhibit growth responses to some antibiotics, but here the mode of action is even less clear. Changes in the rumen metabolites and flora are likely to occur, and hypotheses trying to explain the antibiotic growth response in ruminants are largely based on altered rumen fermentation ${ }^{1}$. No consistent changes in rumen or host metabolism have so far been demonstrated, however, which could be related to growth responses.

Leskova and Zucker ${ }^{2}$ have recently reported that the growth response of early weaned calves to the new phospholipidantibiotic Diumycin (SFI 80.586) was accompanied by elevated blood glucose levels. This antibiotic has a predominantly Gram-positive spectrum and is not active against protozoa. It is not absorbed and therefore its primary action should be confined entirely to the lumen of the intestinal tract. Antibiotic levels of 5 and 10 p.p.m. in the feed were employed, the lower level corresponding to approximately $0.1 \mathrm{mg}$, or less, per $\mathrm{kg}$ of body weight. The calves were fed a complete pelleted feed (maize $40 \%$, oats $15 \%$, alfalfa meal $17 \%$, soya bean meal $25 \%$, minerals and vitamins $3 \%$ ) with hay.

The results of two experiments are shown in Figs 1 and 2. Similar increases of weight gains and blood glucose levels have been measured in two additional experiments. There were no changes in serum lactate levels. Serum urea concentration decreased significantly in calves receiving the antibiotic, indicating increased protein synthesis ${ }^{3}$. Diumycin improved feed utilisation in all experiments by 5 to $10 \%$.

Bergman ${ }^{4}$ showed that blood glucose concentration in sheep is closely related to turnover rate of glucose. This implies that the rate of glucose utilisation is dependent on sufficiently high blood glucose levels. It can be assumed that such elevated blood glucose levels also stimulate insulin secretion ${ }^{5}$ and thereby amino acid transfer into cells. These findings would offer an explanation for the growth response to antibiotics in ruminants, which seems, according to general experience, more pronounced when diets with high roughage content are fed. Such diets tend to lead to a relative "glucose deficiency" not

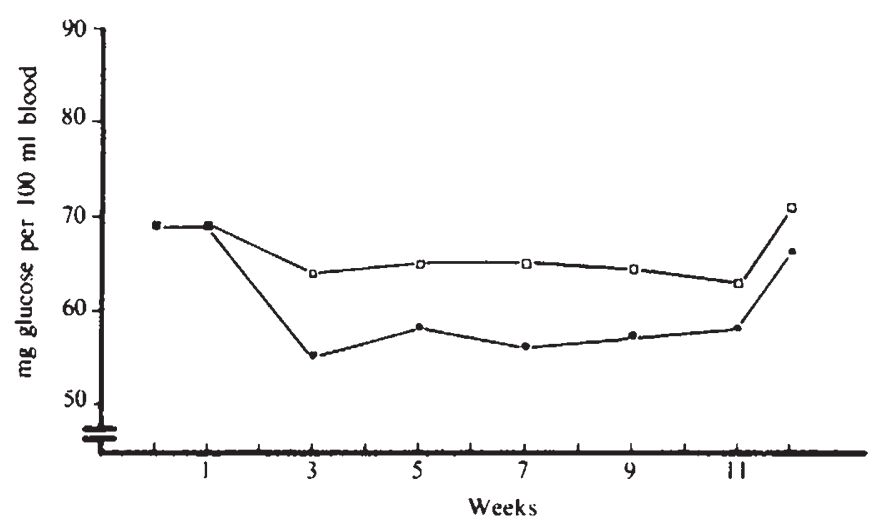

Fig. 1 Effect of Diumycin on growth and blood glucose. Twelve female, individually fed calves (starting weight $68 \mathrm{~kg}$ ) were subjected to each treatment. Concentrates and hay were given ad libitum. With no Diumycin in the feed (O), the average daily gain in body weight was 709 g. With 10 p.p.m. ( $\square$ ) of Diumycin in the foed the average daily gain was $823 \mathrm{~g}$. The arrow indicates the withdrawal of milk replacer.

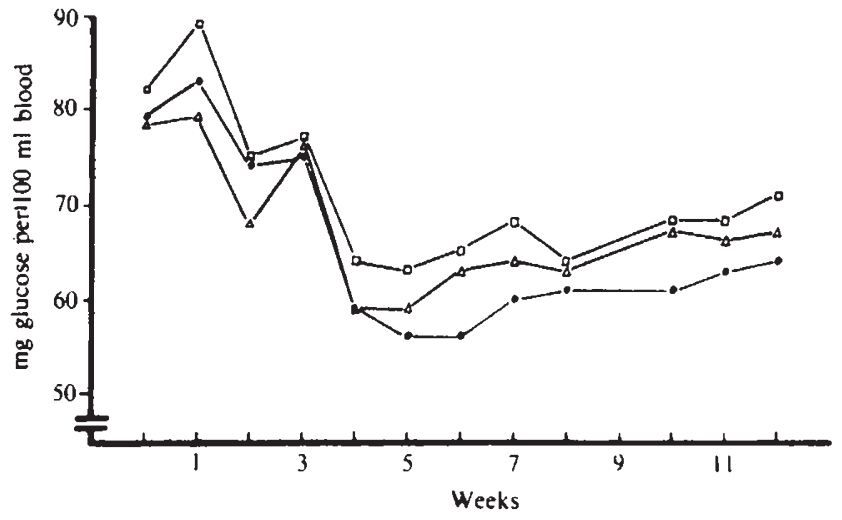

Fig. 2 Relationship between the level of Diumycin in the foed, growth and blood glucose. Sixteen female, individually fed calves (starting weight $61 \mathrm{~kg}$ ) were subjected to each treatment. Concentrates were fed ad libitum but hay was restricted. With no Diumycin in the feed $(O)$, the average daily gain in bodyweight was $680 \mathrm{~g}$; with 5 p.p.m. $(\triangle)$. Diumycin in the feed the gain was $748 \mathrm{~g}$ and with 10 p.p.m. ( $\square$ ) in the foed the gain was $743 \mathrm{~g}$. The arrow indicates the withdrawal of milk replacer.

only by supplying less preformed glucose, but also by favouring formation of acetic acid rather than propionic acid, which is the main precursor of glucose in ruminants.

We conclude that nutritive antibiotic action in the ruminant is related to elevated blood glucose, which may result from either increased rumen synthesis of propionic acid or decreased degradation of starch and sugars in the rumen.

R. LESKOVA

H. ZUCKER

SANDOZ Research Institute,

Brunnerstrasse 59,

A-1235 Vienna

Received September 28, 1973.

1 Preston, T. R., World Review of Nutrition and Dietetics (edit. by Bourne, G. H.), 4, 117 (Pitman Medical Publishing Company, London, 1963).

2 Leskova, R., and Zucker, H., Eur. Nutr. Conf. Cambridge (abstract, in the press).

${ }^{3}$ Zucker, H., Leskova, R., and Tschirch, H., Z. Tierphysiol. Tierernähr, Futtermittelk., 29, 316 (1972).

4 Bergman, E. N., Nature, 202,1333 (1964).

5 Stern, J. S., Baile, C. A., and Mayer, J., Am. J. Physiol., 219, 84 (1970).

\section{Structural Difference between Luminal and Lateral Plasmalemma in Pancreatic Acinar Cells}

The acinar cells of the pancreas, as well as other exocrine protein secreting cells, are highly polarised. Release of secretion products, which occurs by exocytosis (fusion of the secretory granule membrane with the plasmalemma (PM) followed by opening at the point of fusion ${ }^{2}$, is limited to the restricted portion of the cell surface facing the secretory lumen. It is still unclear whether this selective localisation of discharge depends on the specific properties of the luminal portion of the PM. Studies carried out in other cell systerns have indeed revealed that regions of the PM where specialised functions are located can exhibit distinct characteristics ${ }^{2-5}$. But in the pancreas a comparative analysis of the secretory portion of the PM relative to the non-secretory portion has never been reported. By the use of freeze-fracture we have now observed that the luminal PM is different in structure from the remainder of the PM. Rather it is reminiscent of the membrane with which it is functionally associated, the membrane of the zymogen granule $(Z G)$. 